$$
C_{\mathrm{DE} 92000430}^{\operatorname{CONF}-910968--8} 8
$$

\author{
Fusion Energy Program
}

\title{
EX-VESSEL REMOTE MAINTENANCE DEVELOPMENT PLANS FOR THE BURNING PLASMA EXPERMENT
}

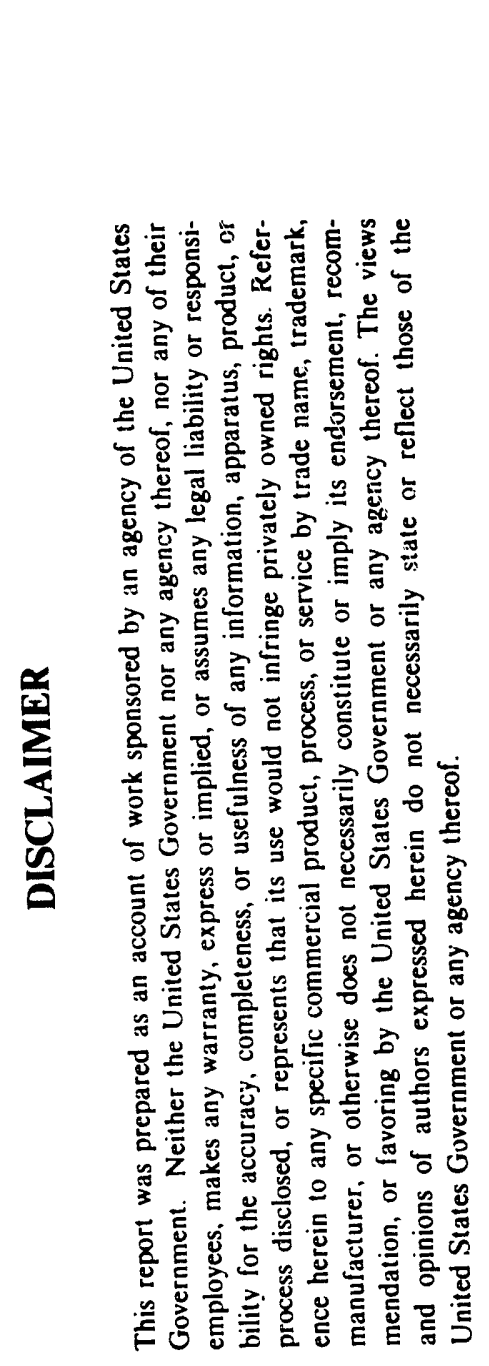

\author{
T.W. Burgess
}

Robotics \& Process Systems Division

and

F.C. Davis

Central Engineering

Oak Ridge National Laboratory ${ }^{\dagger}$

Post Office Box 2008

Oak Ridge, Tennessee 37831-6304

Paper for presentation at the

IEEE/NPSS 14th Symposium of Fusion Engineering

San Diego, California

September 30 - October 3, 1991

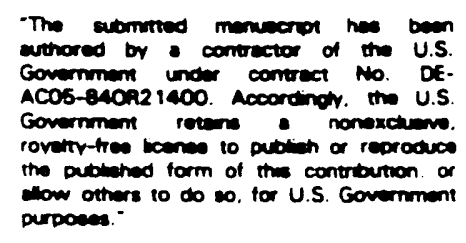

'Research sponsored by the Office of Fusion Energy, U.S. Department of Energy under contract no. DE-AC05-84OR21400 with Martin Marietta Energy Systems, Inc.

'Managed by Martin Marietta Energy Systems, Inc., for the II S. Department of Energy. 


\title{
EX-VESSEL REMOTE MAINTENANCE DEVELOPMENT PLANS FOR THE BURNING PLASMA EXPERIMENT*
}

\author{
T. W. Burgess and F. C. Davis \\ Oak Ridge National Laboratory \\ P.O. Box 2008 \\ Oak Ridge, Tennessee 37831-6304
}

\begin{abstract}
Remote maintenance (RM) is fundamental to the basic design requirements of the Burning Plasma Experiment (BPX), and an extensive $R M$ development and demonstration program is planned to meet these requirements. The program first draws from the experience base that exists in the fission community and Europe's Joint European Torus (JET) Project. Successful solutions are applied where possible and, in many cases, improved in order to achieve the performance demanded by a multiyear program that must be capable of efficiently executing RM procedures. Early, concurrent efforts in the design and fabrication of prototype remote handling ( $\mathrm{RH}$ ) equipment, remote tooling, and maintainable machine components will precede an extensive use of mock-up equipment in order to test, develop, and demonstrate the technology.
\end{abstract}

\section{Introduction}

BPX will be the first fusion device fueled with deuterium-tritium (D-T) gas for the major portion of its operating life. The D-T reactions produce a high energy neutron flux that activates surrounding materials and eliminates the prospect of direct access to the machine for inspection, repair, or modification. The BPX Project has adopted a full RM design philosophy to assure recovery capabilities from all potential failures, in addition to fulfilling the anticipated maintenance requirements [1].

The BPX RM requirements exceed those previously realized. The RM technology currently available has primarily evolved from the nuclear fission industry over the past forty-plus years. In comparison, fusion technology presents many new and unique RM tasks, many of which are more difficult than those previously attempted [2]. The JET Project has expanded and improved this technology base for fusion application [3]

Design solutions from these previous programs will be applied to BPX where possible, but considerable additional development is needed due to the unique and comprehensive RM requirements of this machine. The key technical areas requiring development include manipulation, transport, component RM design, and tooling. This development must take place early enough to support the BPX design activities. This requires an accelerated schedule that includes multiphase, parallel design and development effors as shown in Fig. 1.

\section{Remote Handling System}

The Ex-Vessel Remote Maintenance (EVRM) group is responsible for providing the RH systems required to perform all "ex-vessel" handling and maintenance tasks in the center test cell and in the facility hot cell. Ex-vessel includes all areas external to the vacuum vessel. Extensive development is necessary to produce the $\mathrm{RH}$ systems that are specific to the needs of BPX. This development will lead to the procurement of capital-funded equipment with a degree of assurance that is necessary to provide an integrated system capable of maintaining BPX.

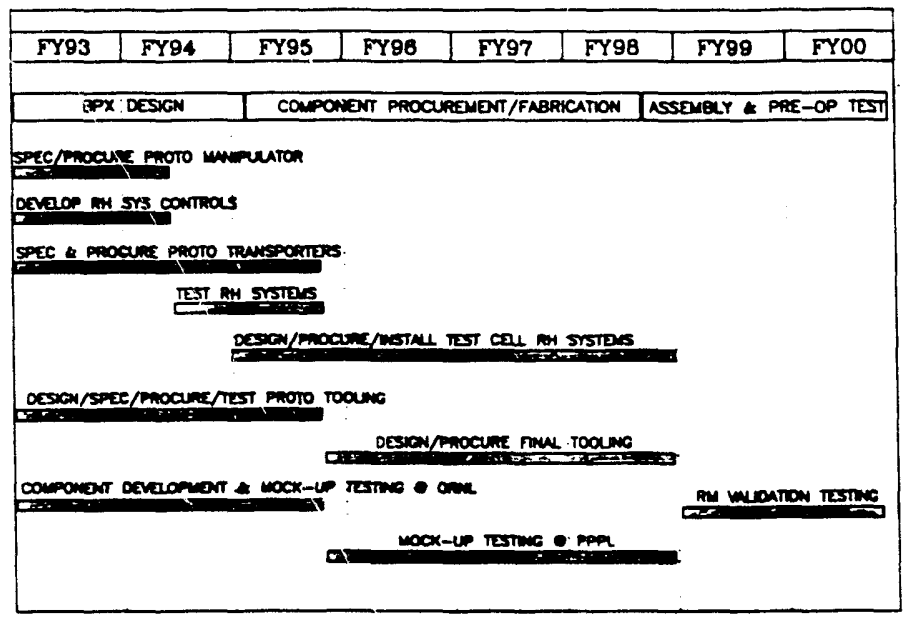

Fig. 1. EVRM development.

During machine operation, the RH systems will be stored in the facility high-bay area located direstly above the machine. Access into the center cell is achieved through a sliding roof shield a? shown in Fig. 2. The high-bay area becomes a no-access area while the center cell roof is open due to the gamma radiation emitted by activated materials. Waste and activated components resulting from maintenance operations are transferred to the facility hot cell through a hatch in the high-bay floor. The remote equipment planned for the hot cell are either commercially available or a product of the center cell systems development. They include a 5-ton crane, a servomanipulator and power manipulator with telescoping tube and bridge transporter, decontanination and waste handling equipment, and through-the-wall master/slave manipulators. After maintenance operations are complete, the roof shield is closed and man-access is restored for hands-on maintenance of the RH systems stored in the high-bay area.

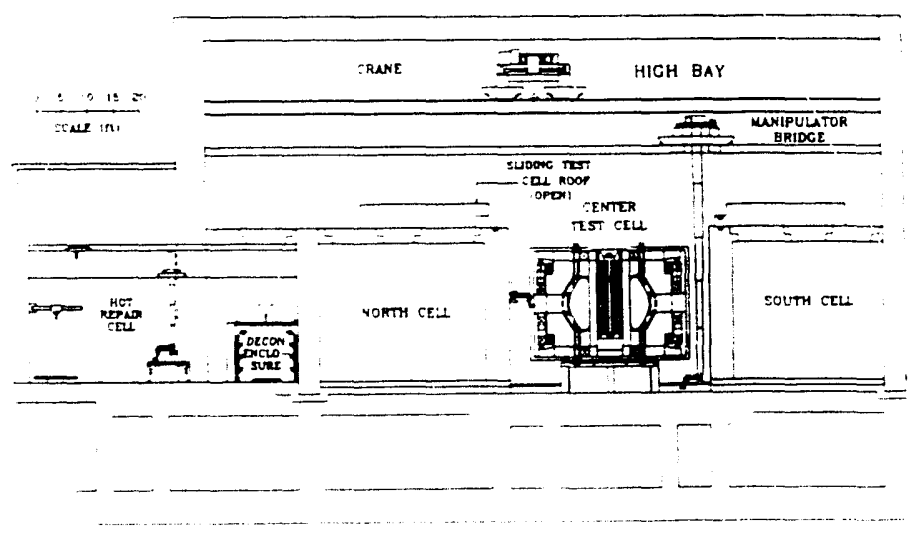

Fig. 2. Test cell and hot repair cell section view.

*Research sponsored by the Office of Fusion Energy, U. S. Department of Energy, under contract DE-AC05-84OR21400 with Martin Marietta Energy Systems, Inc. 
Four independent center cell RH systems are planned as illustrated in Fig. 3. An overhead telescoping tube transporter positions a servomanipulater system above or along side the machine. The "cherry picker" transporter positions a servomanipulator for operations on the lower half of the machine and along the outer periphery of the area beneath the machine. Two manipulators can be deployed beneath the machine; one by means of a vehicle (mobile robot) and the other by an articulated boom manipulator (ABM). The vehicle will provide maximum positioning and access flexibility but will be limited in load handling capabilities. The ABM will include multiple end-effectors for transporting and positioning items that are in excess of the manipulator's capacity. A standard interface package will attach a manipulator to each of the transporters and will include the remote viewing cameras and the camera positioning arms. The $\mathrm{RH}$ system will also include the controls for each of these systems, integrated into four master control stations for simultaneous operation capability from a remote control room. It will also include the closed-circuit television viewing systems and 3-D computer simulations that provide visual and orientation information to the operators.

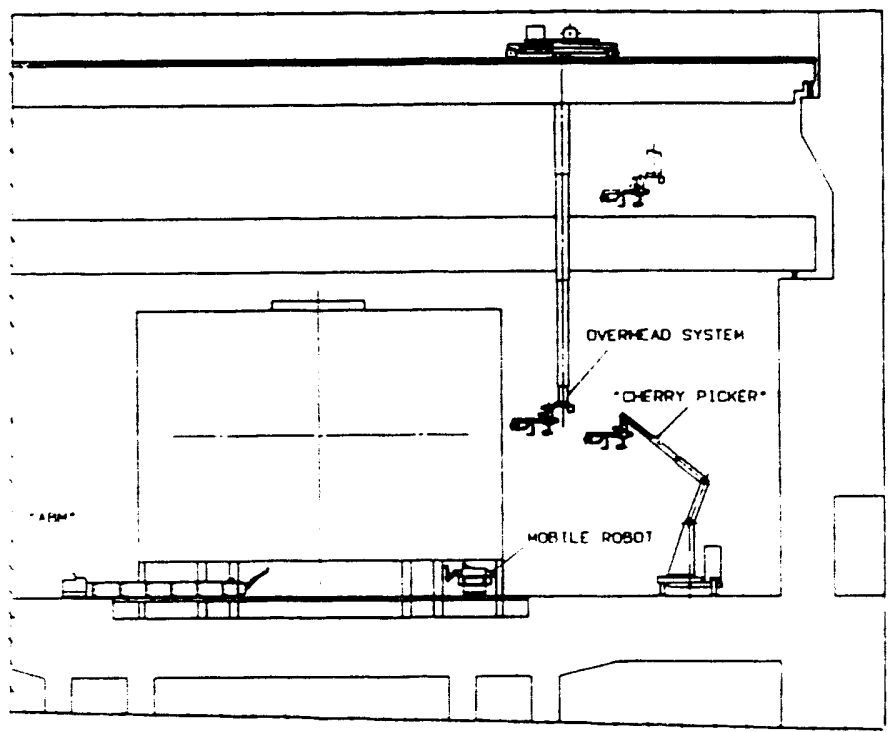

Fig. 3. Remote handling systems.

\section{Servomanipulator Development}

The complexity of the RM tasks and the spatial restrictions to be encountered on BPX dictate a level of compactness and dexterity that exceeds the capabilities of any commercially available servomanipulator system [4]. A system design that meets these requirements will be specified and procured from industry.

The BPX manipulator will consist of a classical mechanical design that offers the best performance in terms of dexterity, stiffness, and force-reflection sensitivity. The latest drive and control technology will be incorporated to improve compactness, load capacity, control flexibility, and automation. A commercial unit is currently being developed for BPX under a Small Business Innovative Research grant [5].

One prototype manipulator is planned for testing and development of the final system design. The prototype unit will initially be installed in RH facilities at Oak Ridge National Laboratory (ORNL), where it will be integrated and tested with the prototype transpert systems. The development and demonstration of control techniques and collision avoidance will also take place at ORNL. Upon completion of this effort (about mid-1995) the protoxype RH systems will be installed in a mock-up RH facility at the BPX Project site for conducting RM tests. Once the protorype unit is fully developed, five additional servomanipulators will be procured for EVRM operations.

\section{Transporter Development}

Effective transport systems are key to the performance of RM operations. Experience from nuclear fuel reprocessing facilities shows that transport and positioning of equipment typically requires $>50 \%$ of the total task completion time. This percentage increases dramatically in fusion facilities where access is more restrictive and positioning is more complex [6]. Spatial constraints also affect operator viewing, further slowing the operation and requiring more flexible and compact camera positioning systems. The fusion application requires transport systems that are more sophisticated than any previously produced. Performance improvements through increased kinematic dexterity, positioning automation, collision avoidance, and computer simulation capabilities are necessary.

One prototype unit of each of the transport systems will be specified and procured from industry to test and develop RM concepts prior to design and procurement of the center cell systems. The prototype units will be initially installed at ORNL for functional testing and demonstration of integrated operation and special control techniques. The prototype $\mathrm{RH}$ systems will eventually be installed in a mock-up facility at the project site for conducting $\mathrm{RM}$ tests and demonstrations during the life of the project.

\section{BPX Remote Maintenance Design}

Major components of the BPX device are shown in Fig. 4. The facility and equipment configurations are reported elsewhere [7]. Major ex-vessel components and systems located in the center cell which require RM include:

- Vac jum vessel extemal

- Thermal shielding (cryostat)

- Toroidal field coils

- Poloidal field coils

- Diagnostic systems

- Ion cyclotron heating systems

- Vacuum pumping and pellet injection piping

- Center cell services and penetrations

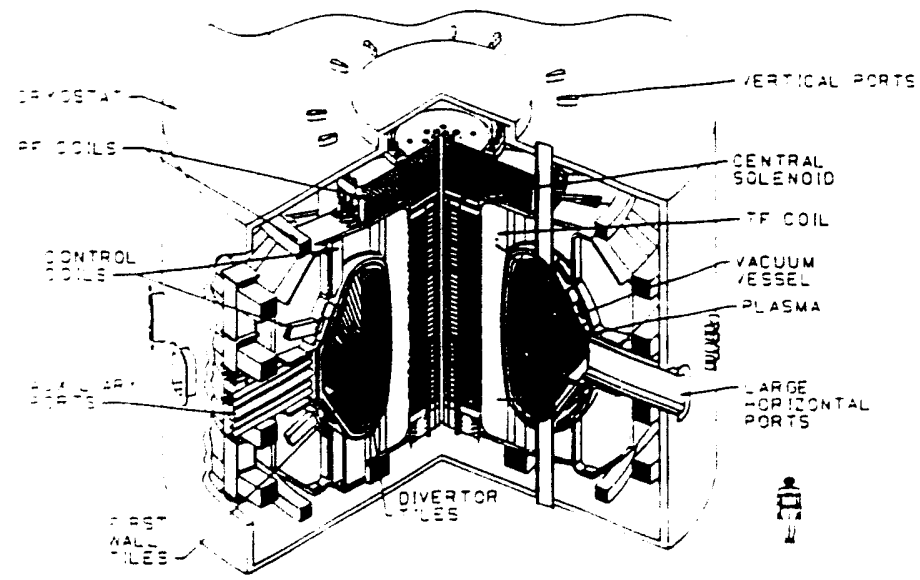

Fig. 4. Burning Plasma Experiment. 


\section{System Design}

Each of the systems just listed is the responsibility of an individual design group which will produce a design that meets the specified functional requireme is s, including RM. The EVRM group provides direct engineering support to each of the groups and is ultimately responsible for ensuring that the systems are remotely maintainable. RM procedures will be verified using component mock-ups and the prototype RH systems.

To produce a design that can be remotely maintained, a system is divided into discrete component modules with physical interfaces that facilitate RM. A module may be composed of several submodules. RM is better described as remote replacement; in situ repair is typically not attempted because it is not cost effective. A failed component is replaced with a spare unit and is later repaired to produce a spare, if cost effective. System components that require frequent maintenance or removal are designed as a single, replaceable module. Frequently replaced or handled components are optimized for $R M$ in order to minimize maintenance times. Components that are not expected to require replacement are less suringently designed for RM. The RM design is guided by the following equipment classifications:

Class 1: Equipment that are essential to BPX operation and safety and are expected to require maintenance. The design of these equipment will be optimized for RM and thoroughly developed and demonstrated.

Class 2: Maintenance is not expected but necessary for the continued operation of BPX. The ability to remotely maintain these devices will be developed and tested. RM optimization is balanced against preparation costs and probable savings in BPX operation time.

Class 3: Although it is not essential to BPX operation, continued use of the equipment is preferred. Standard RM features and procedures are applied with less priority than the first two classes of equipment.

Class 4: RM is positively not needed. This class includes equipment that have very low probability of failure $\left(P>10^{-6}\right)$ and are not essential for continued operation.

\section{Standard Remote Maintenance Features}

An important element of the development program is the design and qualification of the standard RM features that are incorporated in the component modules. This development must be completed early in the component design process and has been initiated on BPX. Examples of such features include the following:

- Mechanical fasteners

- Alignment and handling devices

- Electrical connectors

- Welded and bolted vacuum joints

- Vacuum vessel por windows and feedthroughs

- Cryogenic pipe couplings

Areas such as welding and cutting, cryogenics, and vacuum interfaces are relatively new in the $R M$ field and require a significant development and demonstration effor. As designs are yuailfied, they will be cataloged in the BPX R.M Design Manual for reference and use by the component design groups.
Remote Maintenance Demonstrations

RM of a system and its components must be addressed early in the design stage and verified prior to active operation of the machine. In most cases this requires a demonstration that RM design objectives have been met. This will largely be achieved through the use of mock-ups. Approximately 100 mock-ups have been identified for BPX. Mock-ups may include actual system hardware and/or specially fabricated RM hardware that simulates the component's RM features. Prototype machine components are also used to test RM procedures.

The testing of RM procedures must begin early in the design phase of BPX, well before the prototype RH systems are available for operation. ORNL has an extensive RM development and demonstration facility that will be employed to conduct the initial testing and development programs. The facility will also serve in the initial resting of the prototype RH systems and tooling. The mock-up tests conducted at ORNL will focus on design standards development and the initial RM testing of BPX components.

\section{BPX Mock-Up Facility}

Once the prototype $\mathrm{RH}$ systems have been procured and successfully tested, they will be installed in a dedicated test facility at the project site. This installation is currently planned for mid-1995. Mock-ups of major sections of the machine will be included as shown in Fig. 5. These mock-ups will be designed and procured by the EVRM group in order to provide a representative environment for individual system RM tests and RH system deployment and operation tests. Mock-up tests in this stage of the program will focus on demonstration of comprehensive maintenance procedures. This facility will function through the life of the project for operator training, RM rehearsals, and special development efforts.

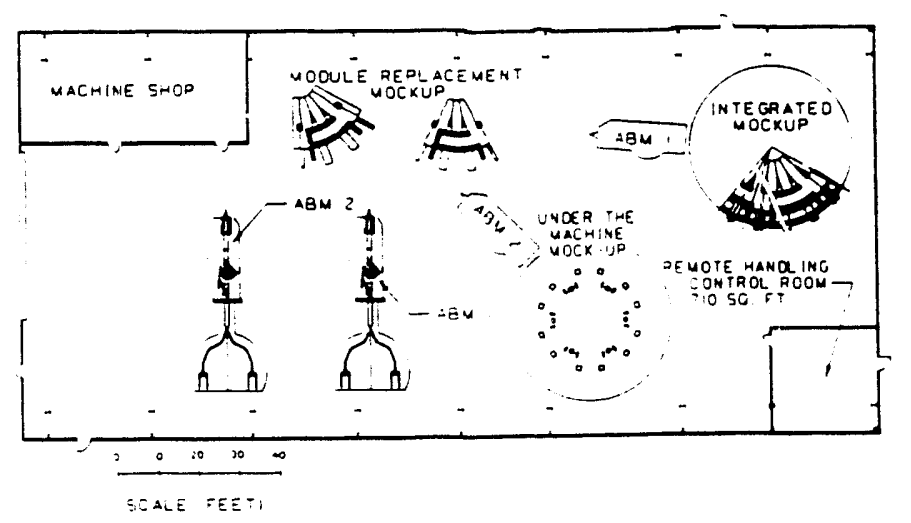

Fig. 5. BFX mock-up facility.

\section{Remote Maintenance Valida!ion Tests}

RM validation testing is conducted in the center cell during and after initial machine assembly us order to check critical points in procedures that have not or cannot be verified through mock-up test programs. The RM of each piece of equipment must be tested and verified pri'r to the active phase of operations. Mock-up tests cannot fully $r t$, present all conditions of the final machine and $\mathrm{RH}$ system design. Foi example, machine assembly will present the only opportunity to handle and position an actual toroidal field (TF) coil module of full weight. About two months of $R M$ validation 
tests are planned during machine assembly. The extent of testing may be increased later when the limitations of the mock-up tests are better quantified through experience.

\section{Remore Tooline Development}

Several types of tools are required to perform BPX RM operations. These tools range from simple to complex and can generally be placed in one of the following categories:

- Fastener operating and torquing tools

- Welding tools

- Cutring tools

- Lifting and handling fixtures and jigs

- Dimension gauges and position mapping tools

The tool inventory for BPX is about 75 individual tools, although tools are standardized in an effort to reduce inventories. Toois are standardized not only to reduce costs but to simplify operations. Standard tools are developed with the standard machine components and cataloged for use by the system design groups.

Unique component designs are unavoidable, and additional special tooling must be developed. For example, the TF coil casing requires a 3-in.-thick structural weld that must be cut and made in the event of TF coil module replacement. The special tooling associated with this task will require considerable development. Lifting and handling fixtures include many examples of special tooling due to the wide variation in mounting position, geometry, and size of BPX system components.

Powered tools can be either electric, hydraulic, or pneumatic. A standard tool service connector similar to the one used by JET is planned for the BPX. The connector is capable of providing electric control and power, pneumatics, high- and low-pressure hydraulics, weld currents, and gases. This connector will be included in the RH system along with the associated control systems.

Prototype tools will be procured based on the complexity and the anticipated development requirements. Welding and cutting are good examples of areas requiring considerable development. Development is also required in areas that might be considered mature. For example, compact, torque and speed controllable nut runner-type wrenches are needed but are not commercially available. Development of general and special tooling will take place during the component ciesign and mock-up testing programs.

\section{Summary}

A considerable RM development program is required and planned for BPX. This program consists of the development and demonstration of RH systems, maintainable component and systems design, and remote tooling. RM involves virtually every element of the project.

Development of each RM technology area will progress in parallel and is important to the early design activities of the project. RM technology from previous nuclear programs will be applied and rerined for the BPX application. Existing RM test facilities will be utilized to test and demonstrate the initial component designs while prototype RH systems and remote tooling are being procured and developed. The prototype $\mathrm{RH}$ systems will be installed in a dedicated test facility at the project site for comprehensive testing and demonstration of $R M$ procedures. $R M$ validation tests in the center cell during machine assembly and prior to active operation of the machine will provide the final demonstration of this technology.

This program will produce the systems and equipment necessary to assure the continued operation of this major step in fusion research. It will also advance RM technology a major step toward that which will be required of subsequent research machines and power reactors.

\section{References}

[1] F. Davis and T. Burgess, "BPX Committed to Total Remote Maintenance," in these proceedings.

[2] F. Davis and D. Kuban, "Remote Maintenance for Fusion: Requirements vs. Technology Gap," Proceedings of the IEEE Thirteenth Symposium on Fusion Engineering, Knoxville, TN, October 2-6, 1989. Vol. 1, pp 251-253.

[3] T. Raimondi, "The JET Remote Mainterance System," Proceedings of the LAEA Technical Meeting, Karlsruhe, FRG, 1989, LAEA-TECDOC-495.

[4] D. Kuban, "Compact Ignition Tokamak Ex-Vessel Manipulator Assessment," CTT internal report. K871211-OR-01, December 1987.

[5] D. Kuban, "A Remote In-Vessel and Ex-Vessel Force Reflecting Telerobotic System for the Burning Plasma Experiment," in these proceedings.

[6] T. Burgess and J. Removille, "Remote Handling System Performance in the PINI Mock-Up Trials," JET internal report, Fusion Technology Division, July 1990.

17] T. Brown, J. Mueller, P. Spampinato, "General Arrangement and System Integration of the BPX," in these proceedings. 

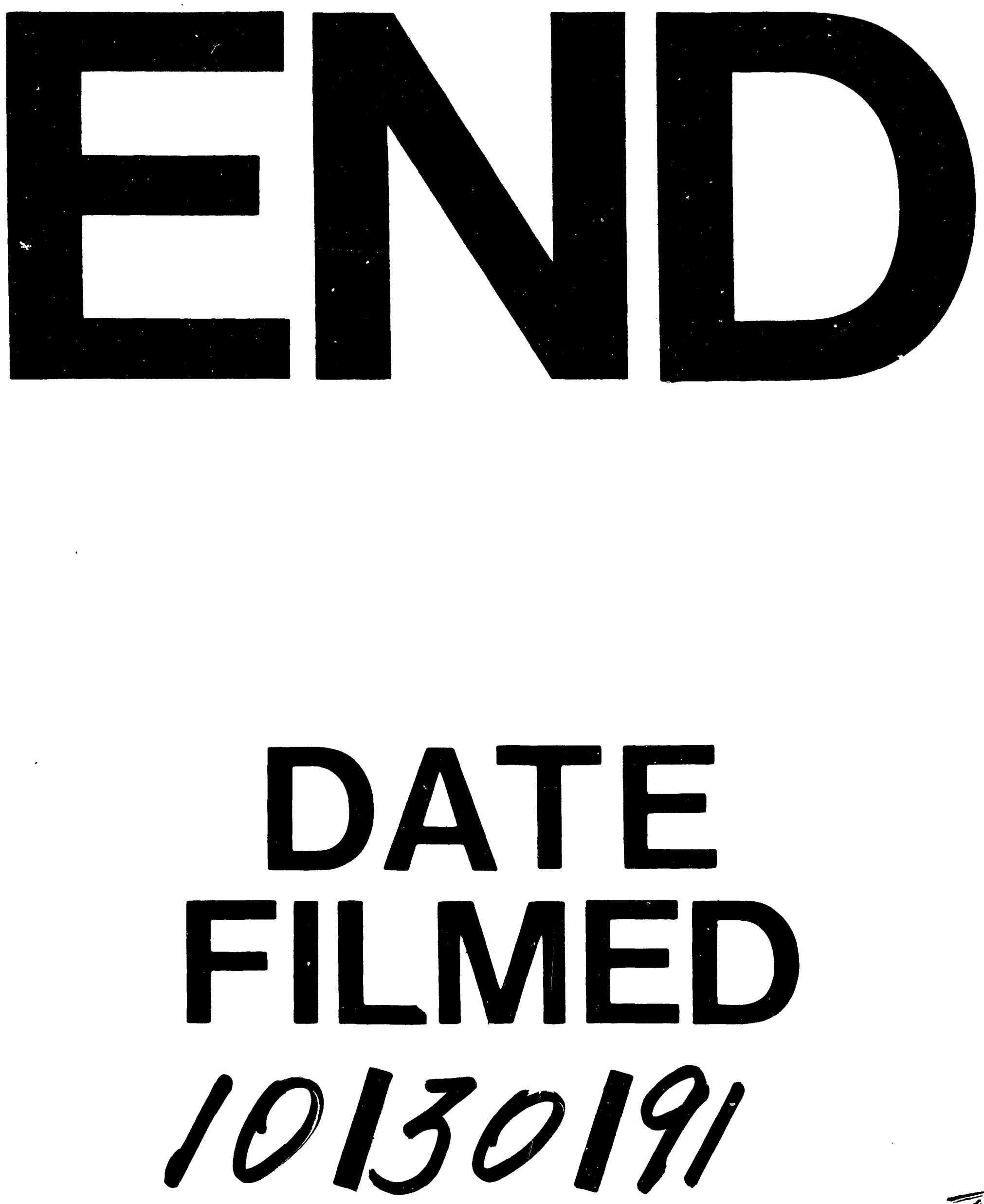

$\bar{I}$ 
